\title{
The lack of specificity of neuropeptide Y (NPY) antisense oligodeoxynucleotides administered intracerebroventricularly in inhibiting food intake and NPY gene expression in the rat hypothalamus
}

\author{
S Dryden, L Pickavance, D Tidd ${ }^{\mathbf{1}}$ and G Williams \\ Diabetes and Endocrinology Research Unit, Department of Medicine and 'School of Biological Sciences, University of Liverpool, Duncan Building, \\ Liverpool L69 3GA, UK \\ (Requests for offprints should be addressed to S Dryden)
}

\begin{abstract}
To evaluate the role of neuropeptide Y (NPY), a potent appetite stimulant, in controlling food intake and body weight, we investigated the use of antisense oligodeoxynucleotides (ODNs) to inhibit NPY gene expression in the hypothalamus. We compared the hypothalamic distribution of fluorescein-labelled ODNs administered intracerebroventricularly, and effects on food intake and NPY gene expression, of three different structural modifications of an antisene ODN sequence against NPY. Rats had either the antisense or missense ODNs $(24 \mu \mathrm{g} /$ day $)$ or saline infused into the third ventricle by osmotic minipumps for 7 days.

The unmodified phosphodiester ODN was not detectable in the hypothalamus after 7 days and had no effects on food intake. The phosphorothioate ODN was widely
\end{abstract}

distributed throughout the hypothalamus but had nonselective effects, with similar changes in food intake and NPY mRNA levels in the antisense and missense groups, and was severely toxic. The propyl-protected ODN appeared to penetrate the hypothalamus well but had no antisense-selective effects on NPY mRNA levels or food intake.

Antisense ODNs are increasingly used to inhibit gene expression in vitro and in intact animals. These negative findings underline the need for rigorous evaluation of any effects of antisense ODNs administered into the central nervous system, and raise doubts about the validity of this approach in physiological or pharmacological studies.

Journal of Endocrinology (1998) 157, 169-175

\section{Introduction}

An antisense oligodeoxynucleotide (ODN) hybridises to and destroys the complementary sequence of its target mRNA, probably because the mRNA-ODN duplex activates ribonuclease H (Giles \& Tidd 1992, Phillips \& Gyurko 1995). Antisense ODNs appear to inhibit gene expression in vitro and under some circumstances in vivo (Bennett 1995, Phillips \& Gyurko 1995). Some reports suggest that ODNs are particularly effective in the central nervous system (CNS), producing selective effects on target genes and specific neuroendocrine consequences. For example, antisense ODNs have been reported to inhibit the expression of neuropeptide Y (NPY) and of the NPY Y1 receptor (Wahlestedt et al. 1993, Xu et al. 1996). Akabayashi et al. (1994) reported reduced food intake and plasma insulin levels, as well as reduced NPY levels in the hypothalamic arcuate nucleus (ARC), the main hypothalamic site of NPY synthesis, after three once-daily injections of a mixture of unmodified (phosphodiester-linked)
ODNs injected directly into the ARC. Similarly, Hulsey et al. (1995) found that a phosphorothioate antisense ODN decreased food intake, body weight and in vitro NPY release from tissue dissected from the paraventricular nucleus.

However, concerns have been raised about the specificity and significance of such effects in intact animals. ODNs can exert important toxic and non-specific sideeffects, and few studies have sought to confirm that antisense ODNs actually enter and interact with their target cells in vivo (Gao et al. 1992, Bennett 1995). Some studies have reported apparent antisense effects of unmodified phosphodiester ODNs (D-ODN) (Bennett 1995, Phillips \& Gyurko 1995), but others have found that D-ODNs are degraded rapidly in vivo and that they may not be effectively taken up into cells (Boado et al. 1995, Szklarczyk \& Kaczmarek 1995, Yaida \& Nowak 1995). Phosphorothioate ODNs (S-ODNs) are able to penetrate brain tissue and are much more stable; significant CNS concentrations can be maintained in vivo over several days 
after intracerebroventricular administration (Whitesell et al. 1993, Bennett 1995, Boado et al. 1995). The main problem with such S-ODNs has been their apparent toxic and other effects, which call into question the specificity of their actions on feeding behaviour (Gao et al. 1992, Bennett 1995).

In these studies, we set out to investigate systematically the possible use of antisense ODNs to target NPY gene expression in the hypothalamus. Neuropeptide $\mathrm{Y}$ is a 36-amino-acid peptide related to pancreatic polypeptide which is concentrated in appetite-regulating areas of the hypothalamus. It is synthesised in neurones of the ARC which project mostly to end in the paraventricular nucleus $(\mathrm{PVN})$ and in the ventromedial (VMH) and dorsomedial (DMH) nuclei (Chronwall et al. 1985, Morris 1989). When injected into the PVN, NPY is an extremely powerful appetite stimulant (Stanley et al. 1986, Dryden et al. 1994), this effect being apparently mediated by the recently cloned Y5 receptor (Gerald et al. 1996). NPY also reduces energy expenditure through inhibition of the sympathetic nerves that stimulate thermogenesis in brown adipose tissue (Billington et al. 1991). Overall, these changes cause net energy gain, and repeated NPY injection leads to obesity within a few days (Stanley et al. 1986).

The NPYergic ARC-PVN pathway is apparently stimulated under conditions of negative energy balance, such as food restriction and diabetes (Beck et al. 1990, Brady et al. 1990, Kalra et al. 1991, Dryden et al. 1994, Frankish et al. 1995), and it has been suggested that these neurones may serve a homeostatic function to defend body weight (Dryden \& Williams 1996). However, the role of NPY remains unclear, because of the observation that the NPY knockout mouse has normal food intake and body weight (Erickson et al. 1996). Theoretically, transient inhibition of NPY expression in the ARC neurones could allow us to test the hypothesis that NPY is an important regulator of feeding and body weight. At present, this is a potentially useful approach because selective Y5 antagonists are not yet available.

In this study we aimed first to determine the ability of various structurally modified antisense ODNs directed against NPY mRNA to enter the hypothalamus, specifically the ARC, when infused into the third ventricle. Intracerebroventricular infusion was used to prolong the possible contact between the ODN and the hypothalamic tissue, and to avoid damage to the ARC (cf Akabayashi et al. 1994), which could potentially destroy the NPY neurones or their projections to the PVN; such damage per se would be predicted to inhibit feeding. Secondly, we aimed to test the ability of the ODNs to inhibit NPY mRNA in the hypothalamus, the major site of which is in the ARC neurones. Because of controversy over the most effective structural sequence of antisense ODNs, we compared three different structurally modified ODNs, namely unmodified phosphodiester (D-ODN), 3' propyl-protected phosphodiester (P-ODN) and phosphorothioate (S-ODN).

\section{Materials and Methods}

\section{Animals}

Adult male Wistar rats (260-280 g) were obtained from Charles River Ltd (Ramsgate, Kent, UK) and housed in wire-bottomed cages. They were kept at $22 \pm 2{ }^{\circ} \mathrm{C}$ in a room with a $12 \mathrm{~h}$ light: $12 \mathrm{~h}$ darkness cycle (lights on 0900-2100 h). Water and standard laboratory chow (CRM; Biosure, Cambridge, Cambs, UK) were freely available. Food intake and general condition were checked daily, and body weight measured at the start and at the end of the study.

\section{Oligodeoxynucleotides}

The antisense oligodeoxynucleotide sequence (Oswell DNA, Southampton, Hants, UK) utilised is complementary to NPY mRNA, extending 20 bases $3^{\prime}$ from the initiation codon (GTT ACC TAG CAT CAT GGC GG). This sequence was not recognised for any other genes in the rodent GENEBANK database. The unmodified D-ODN comprised these bases linked by phosphodiester groups. The modified ODNs had either a propyl group attached to the $3^{\prime}$ end of the above sequence (P-ODN), or phosphorothioate substitutions between the bases ( $\mathrm{S}$ ODN). Control ODNs utilised a scrambled sequence (GTC CAG TGA CTT GCA GTC GA) with or without $3^{\prime}$-propyl protection or phosphorothioate substitution.

With the incisor bar set $3 \mathrm{~mm}$ below the horizontal plane, rats had a $10-\mathrm{mm}$ connector cannula (Plastics One 322OP/SP; Semat Technical, St Albans, Herts, UK) implanted into the third ventricle at the ARC $(3.3 \mathrm{~mm}$ caudal to bregma, in the midline; Paxinos \& Watson 1986), under diazepam-Hypnorm anaesthesia. This was attached via PE tubing $(0.76 \mathrm{~mm}$ i.d.; Portex, Folkestone, Kent, UK) to an Alzet 2001 osmotic minipump (Charles River Ltd) placed between the scapulae. Initially, the pumps were filled with saline and were then replaced after 3 days, under brief anaesthesia, with other pumps containing the respective ODNs.

\section{Experimental protocol}

Distribution of brain uptake and ODN survival Antisense and misssense D-ODN, P-ODN and S-ODNs (in isotonic saline, $12 \mu \mathrm{g} /$ day or $24 \mu \mathrm{g} /$ day) or saline ( $n=8$ /group) were administered for 7 days. The ODNs were all labelled at the $5^{\prime}$ end with fluorescein (Oswell DNA), to allow their tissue penetration to be mapped. Previous studies have shown that fluorescein tagging at this 

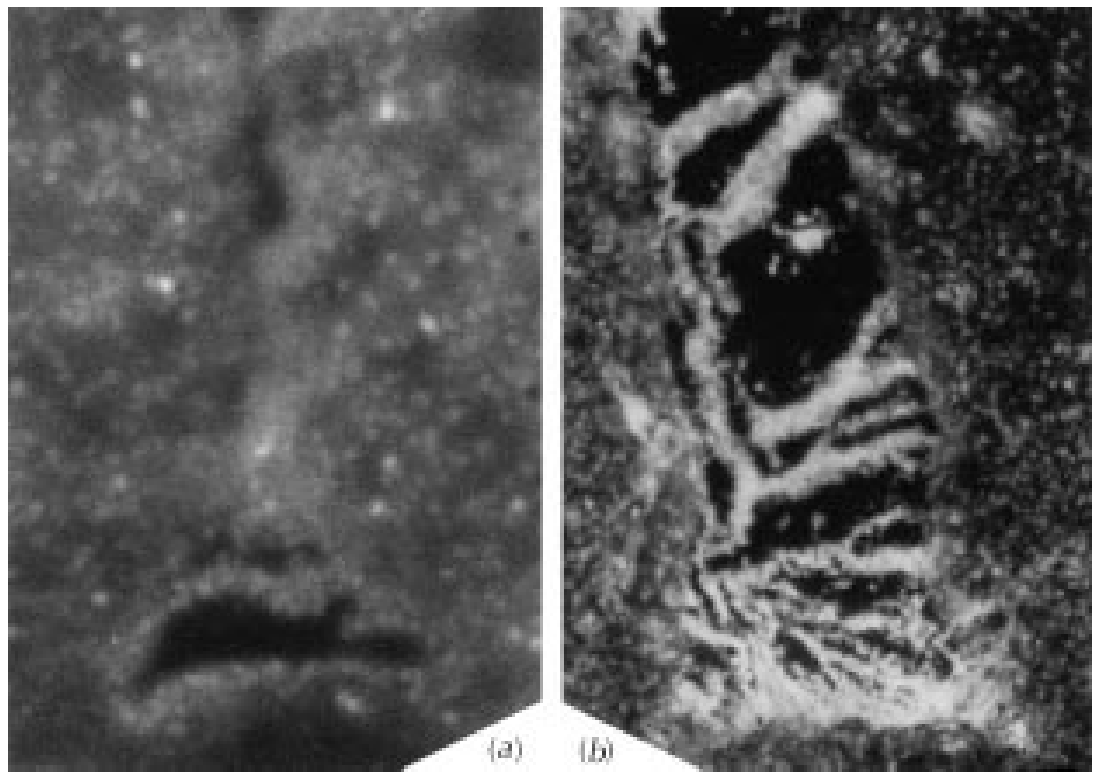

Figure 1 Fluorescence distribution in the hypothalamus after 7 days administration ( $24 \mu \mathrm{g} /$ day) of (a) antisense P-ODN and (b) antisense S-ODN (magnification $\times 375)$.

position does not interfere with the antisense activity of the ODNs in vitro (Spiller \& Tidd 1992). The animals were killed by $\mathrm{CO}_{2}$ inhalation and the brains removed and frozen on dry ice. In eight rats from each group, ten $15 \mu \mathrm{m}$ sections were then cut from the region of the block containing the hypothalamus and immediately visualised under an ultraviolet microscope and photographs taken to localise the fluorescence. Adjacent sections were also taken and stained using 1\% cresyl violet to identify the corresponding hypothalamic nuclei and regions.

In a second study, antisense D-ODN, P-ODN and S-ODNs (in isotonic saline $24 \mu \mathrm{g} /$ day; $n=4$ /group) were administered for 7 days, when the animals were killed and the brains removed and frozen on dry ice. Anionexchange high-pressure liquid chromatography (HPLC) was carried out on samples of the D-ODN, P-ODN, S-ODN and hypothalamic samples from each of the ODN-treated groups. This was performed on an HRLC MA7P weak anion exchange column (Bio-Rad Laboratories Ltd, Hemel Hempstead, Herts, UK) and on a $25 \mathrm{~cm}$ Partisil 10 SAX, strong anion exchange analytical column (Whatman Ltd, Maidstone, Kent, UK) as previously described (Spiller \& Tidd 1992). The column was linked to a fluorescence detector (FS970 L.C. fluorometer, Schoffel Instruments, UK) and the positions of the respective antisense D-ODN, P-ODN and S-ODNs were compared with those produced from the hypothalamic samples from the corresponding ODN-treated rats.

Effects on NPY mRNA levels Rats ( $n=8$ /group) were given $24 \mu \mathrm{g} /$ day of either the D-ODN, P-ODN or
S-ODN antisense or missense (scrambled) sequence, or saline for 7 days.

Rats were killed and plasma was separated and stored at $-40{ }^{\circ} \mathrm{C}$. To measure NPY mRNA, a block of mediobasal hypothalamic tissue was dissected, snap-frozen in liquid nitrogen and stored at $-70{ }^{\circ} \mathrm{C}$ as previously described (Dryden et al. 1996).

RNA was extracted using the guanidinium thiocyanatephenol-chloroform method, loaded for electrophoresis on to a MOPS-formaldehyde-agarose denaturing gel and transferred to a Hybond-N membrane (Amersham International, Amersham, Bucks, UK) by capillary blotting (Dryden et al. 1996). RNA was then fixed by UV crosslinking before hybridisation with a ${ }^{32} \mathrm{P}$-labelled NPY cDNA probe $(0.51 \mathrm{~kb}$, kindly provided by Dr S L Sabol, $\mathrm{NIH}$, Bethesda, MD, USA). Hybridisation was carried out at $68^{\circ} \mathrm{C}$ for $1 \mathrm{~h}$ using $4 \mathrm{ml}$ Qwikhyb hybridisation solution (Stratagene, Cambridge, Cambs, UK) and $200 \mu \mathrm{l}$ denatured salmon sperm DNA. Membranes were then washed at room temperature and $60{ }^{\circ} \mathrm{C}$ in a solution of $2 \times \mathrm{SSC}$ and $0 \cdot 1 \%$ SDS, and two further washings carried out at $60{ }^{\circ} \mathrm{C}$ in $1 \times$ SSC and $0 \cdot 2 \times$ SSC. The filters were exposed overnight to X-ray film and the densities of the autoradiographic bands were measured by densitometry. The signal intensities were normalised against that of tubulin mRNA using a ${ }^{32} \mathrm{P}$-labelled $\alpha$-tubulin probe $(1.4 \mathrm{~kb}$, kindly provided by Prof. J Crampton, Liverpool, UK).

Insulin concentrations were measured using a commercial radioimmunoassay kit (Pharmacia, St Albans, Herts, UK) with an intra-assay coefficient of variation of 5\%. Plasma glucose was determined by an enzymatic kit (Boehringer Mannheim, Lewes, East Sussex, UK). 


\section{Statistical analyses}

Data are shown as means \pm s.E.M. All metabolic and NPY mRNA levels were analysed using one-way analysis of variance coupled to a post-hoc Bonferroni modified $t$-test. A significance level of $P<0 \cdot 05$ was chosen for all comparisons.

\section{Results}

Fluorescence distribution and ODN survival studies

In both the antisense and missense D-ODN-treated groups, no fluorescence was observed in the brain. After administration of the P-ODN fluorescence was visible in the brain in the area of the third ventricle and in an approximately circular profile $(\sim 2 \mathrm{~mm}$ diameter $)$ in the surrounding hypothalamus. However, there was no greater uptake in the ARC and none was found convincingly in the nuclei of the NPY neurones (Fig. 1a).

Following S-ODN administration, intense fluorescence was observed in the areas surrounding the third ventricle, extending to include the whole hypothalamic region (Fig. 1b).

The D-ODN and P-ODN produced fluorescence peaks in the same position, but there was no fluorescence peak from the hypothalamus of the antisense D-ODNtreated rats compared with the pure D-ODN. The fluorescence peak produced from the hypothalami of the $\mathrm{P}-\mathrm{ODN}$-treated rats corresponded to that of the P-ODN sample (Fig. 2). The fluorescence peak produced from the S-ODN-treated rat hypothalamic samples was too high to be measured.

\section{Food intake and metabolic data (Table 1)}

D-ODN-treated rats There were no significant differences in total food intake between animals given $12 \mu \mathrm{g} /$ day ODNs and controls. Similarly, there were no significant differences in body weight, plasma insulin or glucose levels. Nor were there any significant effects on any of these measures at the higher dosage $(24 \mu \mathrm{g} / \mathrm{day})$.

P-ODN-treated rats The rats given antisense ODN lost weight over 7 days $(6 \%$ fall, $P<0.05)$, and showed a significant decrease in food intake ( $9 \%$ decrease, $P<0 \cdot 05)$ compared with saline-treated controls (Fig. 3). There were no differences in food intake and final body weight between the antisense and missense ODN-treated groups, but the missense-treated group failed to gain weight compared with the saline-treated controls. Plasma insulin and glucose levels were lower in the antisense ODN-treated group compared with controls, but these differences fell short of significance $(P>0 \cdot 05)$.

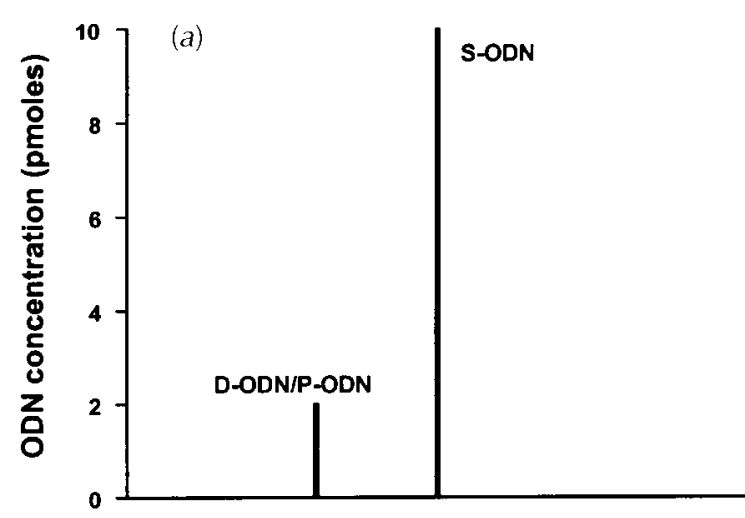

HPLC fraction
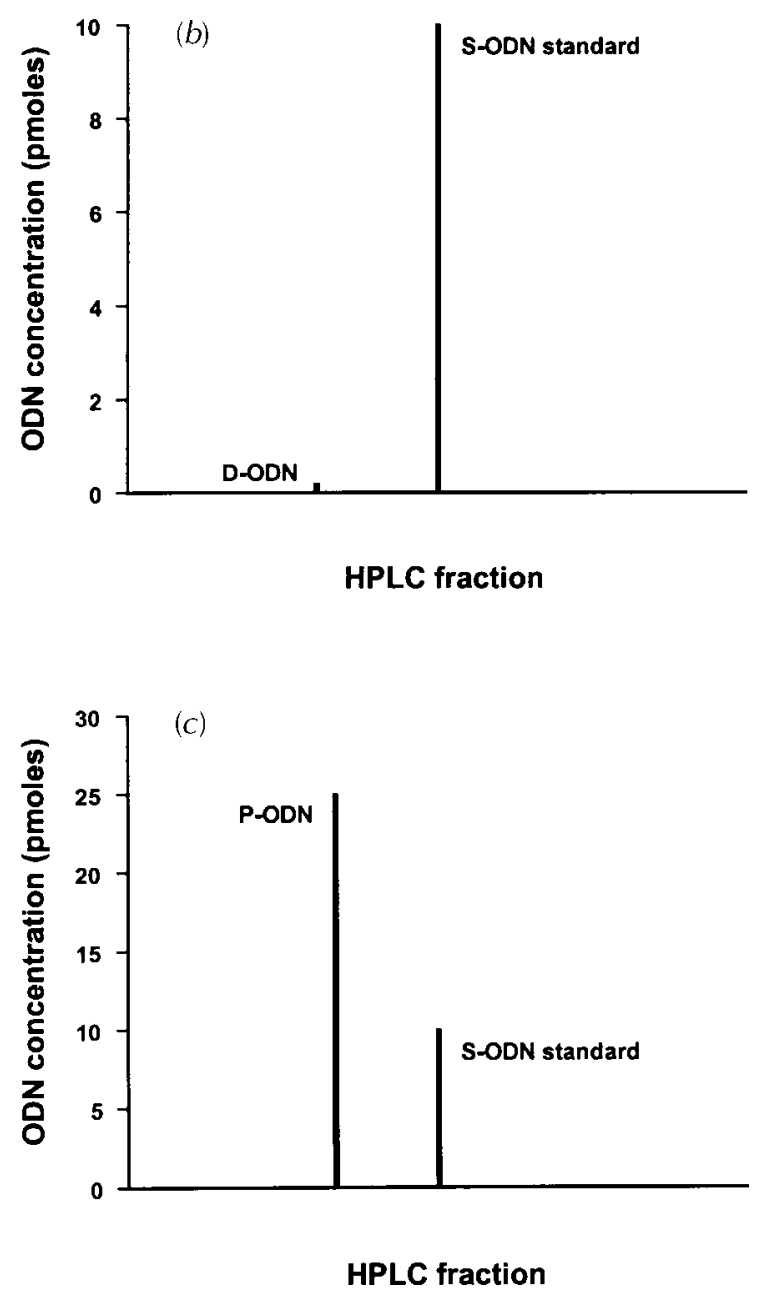

Figure $2 \mathrm{HPLC}$ /fluorometer analysis of (a) antisense D-ODN, $\mathrm{P}-\mathrm{ODN}$ and S-ODNs, and hypothalamic tissue from $(b)$ antisense D-ODN-treated and $(c)$ antisense P-ODN-treated rats (with S-ODN as standard). 
Table 1 Food intake, body weight, and plasma hormone levels in D-ODN-, P-ODN- and $\mathrm{S}-\mathrm{ODN}$-treated rats. Missense or antisense ODNs $(24 \mu \mathrm{g} /$ day $)$ or saline were infused into the third ventricle for seven days. Results are means \pm S.E.M. for $n=8$ rats

\begin{tabular}{|c|c|c|c|}
\hline & Saline & Missense & Antisense \\
\hline \multicolumn{4}{|l|}{ D-ODN } \\
\hline Initial body weight (g) & $266 \pm 7$ & $265 \pm 5$ & $263 \pm 4$ \\
\hline Final body weight (g) & $280 \pm 8$ & $277 \pm 5$ & $275 \pm 4$ \\
\hline Daily food intake (g/day) & $27 \cdot 3 \pm 0 \cdot 8$ & $27 \cdot 8 \pm 1 \cdot 2$ & $26 \cdot 4 \pm 0 \cdot 9$ \\
\hline Insulin (mU/l) & $21 \cdot 3 \pm 6 \cdot 3$ & $24 \cdot 9 \pm 2 \cdot 1$ & $25 \cdot 0 \pm 6 \cdot 1$ \\
\hline Glucose $(\mathrm{mmol} / \mathrm{l})$ & $7 \cdot 8 \pm 0 \cdot 3$ & $8 \cdot 4 \pm 0 \cdot 2$ & $8 \cdot 2 \pm 0 \cdot 1$ \\
\hline \multicolumn{4}{|l|}{ P-ODN } \\
\hline Initial body weight (g) & $265 \pm 5$ & $267 \pm 4$ & $265 \pm 4$ \\
\hline Final body weight (g) & $277 \pm 6$ & $266 \pm 3$ & $260 \pm 2^{*}$ \\
\hline Daily food intake (g/day) & $26 \cdot 9 \pm 1 \cdot 0$ & $25 \cdot 6 \pm 0 \cdot 8$ & $24 \cdot 5 \pm 0 \cdot 7^{*}$ \\
\hline Insulin (mU/l) & $25 \cdot 9 \pm 3 \cdot 6$ & $24 \cdot 9 \pm 2 \cdot 9$ & $21 \cdot 3 \pm 2 \cdot 1$ \\
\hline Glucose $(\mathrm{mmol} / \mathrm{l})$ & $8 \cdot 2 \pm 0 \cdot 2$ & $8 \cdot 0 \pm 0 \cdot 2$ & $7 \cdot 7 \pm 0 \cdot 3$ \\
\hline \multicolumn{4}{|l|}{ S-ODN } \\
\hline Initial body weight (g) & $266 \pm 4$ & $267 \pm 3$ & $264 \pm 4$ \\
\hline Final body weight (g) & $280 \pm 7$ & $242 \pm 2^{* *}$ & $241 \pm 6^{* *}$ \\
\hline Daily food intake (g/day) & $27 \cdot 1 \pm 1 \cdot 1$ & $23 \cdot 1 \pm 0 \cdot 9^{*}$ & $22 \cdot 2 \pm 0 \cdot 8^{*}$ \\
\hline Insulin (mU/l) & $28 \cdot 4 \pm 2 \cdot 3$ & $19 \cdot 9 \pm 2 \cdot 4^{*}$ & $18 \cdot 6 \pm 3 \cdot 5^{*}$ \\
\hline Glucose $(\mathrm{mmol} / \mathrm{l})$ & $7 \cdot 5 \pm 0 \cdot 5$ & $7 \cdot 5 \pm 0 \cdot 6$ & $6 \cdot 9 \pm 0 \cdot 7$ \\
\hline
\end{tabular}

${ }^{*} P<0 \cdot 5,{ }^{*} P<0 \cdot 01$ vs saline-treated controls.

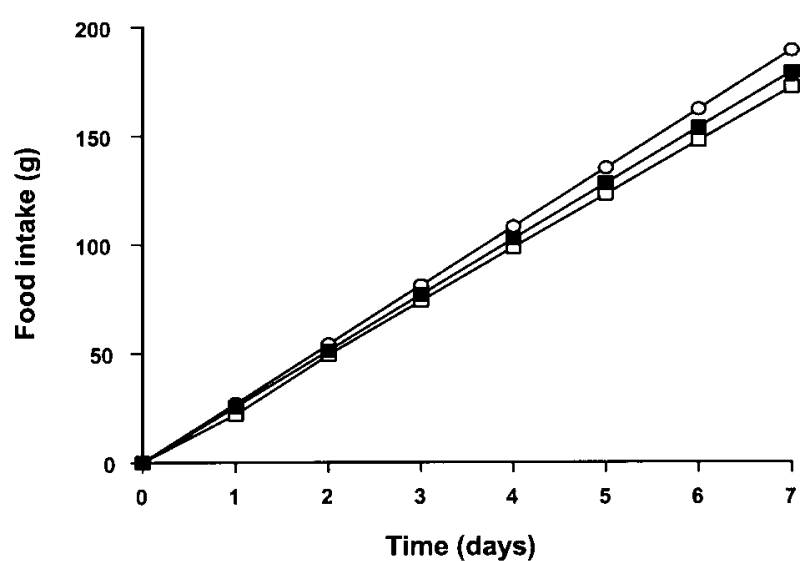

Figure 3 Cumulative food intake in rats treated with saline $(\bigcirc)$, antisense-P-ODN $(\square)$ or missense P-ODN $(\boldsymbol{\square})$.

S-ODN-treated rats All the S-ODN-treated animals (both antisense and missense) appeared listless and clinically unwell after two days of infusion and deteriorated considerably over the seven days of treatment. They stopped displaying normal behaviour, including grooming, and developed an abnormal hunched posture. Both the missense- and antisense-treated rats showed significant and comparable falls in body weight over the 7 days $(12 \%$ and $13 \%$ respectively, $P<0 \cdot 01$ vs baseline) compared with the saline-treated rats. Daily food intake was also significantly reduced in both the antisense and missense ODN-treated groups compared with the saline-treated controls (by 15\% and $18 \%$ respectively, $P<0 \cdot 05)$. Plasma insulin levels were significantly reduced in both antisense- and missensetreated groups compared with controls $(P<0 \cdot 05)$. There were no significant changes in glucose concentrations in either the antisense- or missense-treated groups.

\section{NPY mRNA levels}

There were no significant changes in NPY mRNA levels in the rats given antisense D-ODN compared with the missense- and saline-treated groups (Table 2). Nor were there any significant changes in NPY mRNA levels in the rats given antisense $\mathrm{P}-\mathrm{ODN}$ compared with the missense- and saline-treated groups (Table 2).

NPY mRNA levels were significantly reduced in both the antisense and missense S-ODN-treated rats compared with the saline-treated controls (both $P<0 \cdot 01$ ), but the difference between missense and antisense S-ODNs was not significant $(P>0 \cdot 05)$.

\section{Discussion}

NPY synthesis occurs in the hypothalamus, virtually exclusively in the ARC at the base of the third ventricle, and infusion into the third ventricle should have allowed the respective ODNs to reach the NPY cell bodies located in this region. We were unable to demonstrate selective penetration of ODNs into ARC neurones, or specific inhibition of NPY gene expression or the expected 
Table 2 NPY/tubulin mRNA levels (arbitrary units) in D-ODN-, P-ODN- and S-ODN-treated rats. Missense or antisense ODNs $(24 \mu \mathrm{g} /$ day) or saline were infused into the third ventricle for seven days. Values are means \pm S.E.M. for $n=8$ rats

Ratio NPY/tubulin mRNA

\begin{tabular}{|c|c|c|c|}
\hline & D-ODN & P-ODN & S-ODN \\
\hline Saline-treated & $1 \cdot 36 \pm 0 \cdot 4$ & $0 \cdot 81 \pm 0 \cdot 2$ & $1 \cdot 23 \pm 0 \cdot 3$ \\
\hline Missense ODN & $1 \cdot 3 \pm 0 \cdot 3$ & $0 \cdot 61 \pm 0 \cdot 2$ & $0 \cdot 69 \pm 0.2^{*}$ \\
\hline Antisense ODN & $1 \cdot 25 \pm 0 \cdot 25$ & $0 \cdot 57 \pm 0 \cdot 1$ & $0 \cdot 65 \pm 0.3^{*}$ \\
\hline
\end{tabular}

${ }^{*} P<0.05$ vs saline-treated controls.

behavioural correlate of reduced food intake. These negative findings are clearly at variance with several published papers, in which various antisense ODNs appear to have influenced feeding and the expression of NPY itself and of the NPY Y1 receptor (Akabayashi et al. 1994, Heilig 1995, Hulsey et al. 1995).

The studies using D-ODN strongly suggest that this particular structure is rapidly broken down, as no fluorescence was found in the hypothalamic area after 7 days continuous infusion and no fluorescent peak was obtained by HPLC. Other studies have also found that D-ODNs show poor distribution from the site of administration (Ogawa et al. 1995, Szklarczyk \& Kaczmarek 1995), and are unstable and degraded rapidly in the CNS especially after intracerebral injection (Whitesell et al. 1993, Szklarczyk \& Kaczmarek 1995). The extreme instability of D-ODNs after intracerebral injection may be due to their susceptibility to $3^{\prime}$-exonucleases which are present in the brain and would rapidly break up the bases. This could account for the lack of fluorescence and the lack of effect on NPY mRNA. It is possible that D-ODNs injected directly into the ARC might survive better and so be able to exert physiologically relevant antisense effects (Akabayashi et al. 1994), although this explanation is inconsistent with studies that have specifically compared intracerebral with intracerebroventricular injection (Bennett 1995, Landgraf 1996).

The P-ODN was much more stable after infusion into the third ventricle, showing extensive distribution within the hypothalamus with visually detectable amounts of intact ODN remaining after 7 days and a fluorescence peak corresponding to the pure ODN detected by HPLC. The antisense P-ODN also reduced food intake and body weight over the 7 days, but NPY mRNA levels were unchanged in the antisense-treated group; significantly, the missense P-ODN-treated rats also failed to gain weight, which must indicate non-specific effects. It is possible that a divergence between the effects of the antisense and missense ODNs may also have been visible if lower doses of the ODNs had been used, as were utilised in some other studies, though this could also have resulted in an increase in degradation (Landgraf 1996). Antisense ODNs may also exert various effects by alternative non- antisense mechanisms which do not directly change mRNA levels, such as influencing the maturation of the gene transcript or preventing translation, or even the toxic effects of the bases liberated by degradation of the ODNs (Bennett 1995, Phillips \& Gyurko 1995). Interestingly, one study has found that the stability of S-ODN was significantly reduced if there was even one phosphodiester bond in the ODN, suggesting that the ODN was attacked by an endonuclease (Boado et al. 1995). This could be relevant to the present study if the partial breakdown of the P-ODN at some stage altered its ability to influence NPY mRNA levels.

All the S-ODNs administered for 7 days were found extensively in the hypothalamus and the surrounding tissues and appeared not to be degraded, which is consistent with other studies (Whitesell et al. 1993, Phillips \& Gyurko 1995, Szklarczyk \& Kaczmarek 1995). These very high levels of fluorescence may have been the result of the ODN binding to tissue proteins (Bennett 1995, Phillips \& Gyurko 1995). This is consistent with previous findings by D Tidd \& R V Giles (unpublished observations), and our own cellular distribution study, and probably argues against specific binding of the ODN to NPY or other neurones. The S-ODN reduced food intake, body weight and NPY mRNA levels, but this effect was not confined to the antisense ODN; the missense-treated group displayed similar changes. The S-ODN also induced serious adverse physical and behavioural changes in the rats, indicating significant toxicity. This is consistent with previous observations that such S-ODNs cause numerous non-specific side effects (Gao et al. 1992, Bennett 1995). The importance of the missense control group is clearly shown where the ODN targets a gene involved in non-robust behaviours such as food intake, which might be susceptible to toxic effects of the ODN.

Our findings must cast serious doubt on the ability of antisense ODNs to inhibit target gene expression in the CNS in a sufficiently selective fashion to test physiological hypotheses or to be used therapeutically. In particular, our observations strengthen the view that D-ODNs are so unstable in the brain that they are very unlikely to have any enduring biological activity, while S-ODNs have 
major non-specific effects and are unacceptably toxic. We have no ready explanation for previous studies which reported apparently selective target gene expression. The most promising of the ODNs which we tested was the P-ODN. This had good access to the hypothalamus from the third ventricle, but we did not find any clear evidence that it entered the NPY neurones and it did not produce any selective reduction in NPY mRNA levels at the doses used.

\section{Acknowledgements}

S D was supported by the Wellcome Trust and L P by the BBSRC. We are also grateful to Lynn Vicary for care of the animals, and Professor Julian Crampton and Dr Qiong Wang for help with the molecular biology techniques.

\section{References}

Akabayashi A, Wahlestedt C, Alexander JT \& Leibowitz SF 1994 Specific inhibition of endogenous neuropeptide $\mathrm{Y}$ synthesis in arcuate nucleus by antisense oligonucleotides suppresses feeding behavior and insulin secretion. Molecular Brain Research 21 55-61.

Beck B, Jhanwar-Uniyal M, Burlet A, Chapleur-Chateau M, Leibowitz SF \& Burlet C 1990 Rapid and localized alterations of neuropeptide $\mathrm{Y}$ in discrete hypothalamic nuclei with feeding status. Brain Research 528 245-249.

Bennett MR 1995 The use of antisense oligonucleotides as therapeutic agents: a review. Journal of Drug Development and Clinical Practice 7 225-235.

Billington CJ, Briggs JE, Grace M \& Levine AS 1991 Effects of intracerebro-ventricular injections of neuropeptide $\mathrm{Y}$ on energy metabolism. American Journal of Physiology 260 R321-R327.

Boado RJ, Kang Y-S, Wu D \& Pardridge WM 1995 Rapid plasma clearance and metabolism in vivo of a phosphorothioate oligodeoxynucleotide with a single, internal phosphodiester bond. Drug Metabolism and Disposition 23 1297-1300.

Brady LS, Smith MA, Gold PW \& Herkenham M 1990 Altered expression of hypothalamic neuropeptide Y mRNAs in foodrestricted and food-deprived rats. Neuroendocrinology 52 441-447.

Chronwall BM, Dimaggio DA, Massari VJ, Pickel VM, Ruggiero DA \& O'Donohue TL 1985 The anatomy of neuropeptide Y-containing neurons in the rat brain. Neuroscience 15 1159-1181.

Dryden S \& Williams G 1996 The role of hypothalamic peptides in the control of energy balance and body weight. Current Opinion in Endocrinology and Diabetes 3 51-58.

Dryden S, Frankish HM, Wang Q \& Williams G 1994 Neuropeptide $\mathrm{Y}$ and energy balance: one way ahead for the treatment of obesity? European Journal of Clinical Investigation 24 293-308.

Dryden S, Frankish HM, Wang Q, Pickavance L \& Williams G 1996 The serotonergic agent fluoxetine reduces neuropeptide $\mathrm{Y}$ levels and neuropeptide $\mathrm{Y}$ secretion in the hypothalamus of lean and obese rats. Neuroscience 72 557-566.

Erickson JC, Clegg KE \& Palmiter RD 1996 Sensitivity to leptin and susceptibility to seizures of mice lacking neuropeptide Y. Nature 381 415-418.

Frankish HM, Dryden S, Hopkins D, Wang Q \& Williams G 1995 Neuropeptide $Y$, the hypothalamus and diabetes: insights into the control of metabolism. Peptides 16 757-771.

Gao W-Y, Han F-S, Storm C, Egan W \& Cheng Y-C 1992 Phosphorothioate oligonucleotides are inhibitors of human DNA polymerase and RNase $\mathrm{H}$ : implications for antisense technology. Molecular Pharmacology 41 223-229.

Gerald C, Walker MW, Criscione L, Gustafason EL, Batzl-Hartmann C, Smith KE, Vaysse P, Durkin MM, Laz TM, Linemeyer DL, Schaffhauser AO, Whitbread S, Hofbauer KG, Taber RI, Branchek TA \& Weinshank RL 1996 A receptor subtype involved in neuropeptide Y-induced food intake. Nature 382 168-171.

Giles RV \& Tidd D 1992 Increased specificity for antisense oligodeoxynucleotide targeting of RNA cleavage by RNase $\mathrm{H}$ using chimeric methylphosphonodiester/phosphodiester structures. Nucleic Acid Research 20 763-770.

Heilig M 1995 Antisense inhibition of neuropeptide Y (NPY)-Y1 receptor expression blocks the anxiolytic-like action of NPY in amygdala and paradoxically increases feeding. Regulatory Peptides $\mathbf{5 9}$ 201-205.

Hulsey MG, Pless CM, White BD \& Martin RJ 1995 ICV administration of anti-NPY antisense oligonucleotide: effects on feeding behavior, body weight, peptide content and peptide release. Regulatory Peptides 59 207-214.

Kalra SP, Dube MG, Sahu A, Phelps C \& Kalra PS 1991 Neuropeptide Y secretion increases in the paraventricular nucleus in association with increased appetite for food. Proceedings of the National Academy of Sciences 38 10931-10935.

Landgraf R 1996 Antisense targetting in behavioural neuroendocrinology. Journal of Endocrinology 151 333-340.

Morris BJ 1989 Neuronal localisation of neuropeptide Y gene expression in rat brain. Journal of Comparative Neurology 290 358-368.

Ogawa S, Brown HE, Okano HJ \& Pfaff DW 1995 Cellular uptake of intracerebrally administered oligodeoxynucleotides in mouse brain. Regulatory Peptides 59 143-149.

Paxinos G \& Watson C 1986 The Rat Brain in Stereotaxic Coordinates, edn 2. Sydney: Academic Press.

Phillips MI \& Gyurko R 1995 In vivo applications of antisense oligonucleotides for peptide research. Regulatory Peptides $\mathbf{5 9}$ 131-141.

Spiller DG \& Tidd DM 1992 The uptake kinetics of chimeric oligodeoxynucleotide analogues in human leukaemia MOLT-4 cells. Anti Cancer Drug Design 7 115-129.

Stanley BG, Kyrkouli SE, Lampert S \& Leibowitz SF 1986 Neuropeptide Y chronically injected into the hypothalamus: a powerful neurochemical inducer of hyperphagia and obesity. Peptides 7 1189-1192.

Szklarczyk A \& Kaczmarek L 1995 Antisense oligodeoxynucleotides: stability and distribution after intracerebral injection into rat brain. Journal of Neuroscience Methods 60 181-187.

Wahlestedt C, Pich EM, Koob GF, Yee F \& Heilig M 1993 Modulation of anxiety and neuropeptide Y-Y1 rceptors by antisense oligodeoxynucleotides. Science 259 528-531.

Whitesell L, Geselowitz D, Chavany C, Fahmy B, Waldbridge S, Alger JR \& Neckers LM 1993 Stability, clearance, and disposition of intraventricularly administered oligodeoxynucleotides: implications for therapeutic application within the central nervous system. Proceedings of the National Academy of Sciences 90 4665-4669.

Xu B, Sahu A, Kalra PS, Crowley WR \& Kalra SP 1996 Disinhibition from opioid influence augments hypothalamic neuropeptide Y (NPY) gene expression and pituitary luteinizing hormone release: effects of NPY messenger ribonucleic acid antisense oligodeoxynucleotides. Endocrinology 137 78-84.

Yaida Y \& Nowak TS Jr 1995 Distribution of phosphodiester and phosphorothioate oligonucleotides in rat brain after intraventricular and intrahippocampal administration determined by in situ hybridization. Regulatory Peptides 59 193-199.

Received 12 September 1997

Accepted 21 November 1997 